\title{
Effect of angiopoietin-like protein 4 on rat pulmonary microvascular endothelial cells exposed to LPS
}

\author{
YUXI WANG $^{1}$, HAILONG CHEN $^{2}$, HAILONG LI $^{1,4}$, JINGWEN ZHANG $^{1}$ and YANYAN GAO ${ }^{3}$ \\ ${ }^{1}$ Dalian Medical University; ${ }^{2}$ Department of General Surgery, The First Affiliated Hospital of Dalian Medical University; \\ ${ }^{3}$ Department of Central Laboratory, Dalian Municipal Central Hospital, Dalian, Liaoning, P.R. China; \\ ${ }^{4}$ Dalton Cardiovascular Research Center, University of Missouri, MO, USA
}

Received March 11, 2013; Accepted June 13, 2013

DOI: $10.3892 /$ ijmm.2013.1420

\begin{abstract}
Pulmonary microvascular endothelial cells (PMVECs) possess highly proliferative and angiogenic capacities and are localized at the critical interface between the blood and microvessel wall; they are the primary targets of inflammatory cytokines during lung inflammation. Angiopoietin-like protein 4 (Angptl4) is a circulating protein that has recently been implicated in the regulation of angiogenesis and metastasis. This study aimed to investigate the effect of Angptl4 on rat PMVECs (RPMVECs) exposed to lipopolysaccharide (LPS). The cell culture was stimulated with LPS. Total Angptl4 cDNA was obtained from Source BioScience. The PCR product was cloned into the pcDNA3.1-eGFP or the pcDNA3.1-eGFP-Angpt14 vector, which were then transfected into the RPMVECs using SuperFect transfection reagent. The Angpt14 mRNA levels, protein levels and cell morphology of the RPMVECs in the experimental groups were detected using real time-PCR, western blot analysis, MTT assay, ELISA and confocal microscopy methods, respectively. The Angptl4 expression vector, pcDNA3.1-eGFP-Angpt14, was successfully constructed. The Angptl4 mRNA level in the LPS-pcDNA3.1eGFP-transfected group (blank control) was slightly increased and was significantly higher in the experimental group compared with the empty vector and blank control group with significant differences. Pro-apoptotic caspase-8, -9 and Bax protein were inhibited, while $\mathrm{p}-\mathrm{AKT} / \mathrm{AKT}$ and $\mathrm{p}-\mathrm{MEK} 1 / 2$ protein expression was also decreased. The rosiglitazone group had significantly decreased levels of the inflammatory cytokine, tumor necrosis factor $(\mathrm{TNF})-\alpha(\mathrm{P}<0.01)$. The overexpression of Angptl4 inhibited the LPS-induced increase in the permeability of the RPMVECs, which was associated with the depolymerization of central F-actin in the RPMVECs. In conclusion, our study
\end{abstract}

Correspondence to: Dr Hailong Chen, Department of General Surgery, The First Affiliated Hospital of Dalian Medical University, 222 ZhongShan Road, Dalian, Liaoning 116011, P.R. China

E-mail: chenhailong2012@yahoo.com.cn

Key words: angiopoietin-like protein 4, pulmonary microvascular endothelial cell, acute lung injury, F-actin demonstrates that the overexpression of Angptl4 exerts protective, anti-inflammatory and anti-angiogenic effects. It represents a novel therapeutic target gene for the treatment of acute lung injury induced by LPS.

\section{Introduction}

Angiopoietin-like 4 (Angpt14), one of the key components of the renin-angiotensin system, regulates glucose homeostasis, insulin sensitivity and lipid metabolism (1-4). This multi-functional hormone also affects the proliferation and apoptosis of vascular endothelial cells. A recent study demonstrated that the overexpression of Angptl4 impairs tumor growth associated with enhanced apoptosis, and plays a role in the inflammatory response; however, the mechanisms involved remain unknown (5). Angptl4 expression is upregulated under a variety of conditions, including treatment with glucocorticoids, peroxisome proliferator-activated receptor (PPAR) agonists and transforming growth factor- $\beta$ (TGF- $\beta$ ) (6-9). Moreover, the expression of Angptl4 is markedly induced under ischemic and hypoxic conditions (10).

Acute lung injury (ALI) is a very common clinical presentation characterized by severe clinical symptoms. Lipopolysaccharide (LPS), a major component of Gramnegative bacterial outer membranes, is an endotoxin which is believed to be the main initiator for the microcirculatory abnormalities in septic ALI (11). It has been reported that Angptl4 is a downstream target gene of the ligand-activated transcription factor, PPAR- $\gamma$ (12). Studies have shown that PPAR- $\gamma$ plays an anti-inflammatory role in gastric inflammation induced by ischemia/reperfusion (I/R) (13-17), aspirin (18) and Helicobacter pylori infection (19) in rats. The PPAR- $\gamma$ ligand, troglitazone, has been shown to markedly decrease the severity of pancreatic and pulmonary injury in acute pancreatitis (AP) by reversing the increase in the mRNA expression of the pro-inflammatory cytokines, interleukin (IL)-6 and tumor necrosis factor (TNF)- $\alpha$, in cerulean-induced pancreatitis in mice (20). The lung microvascular endothelial cell response to sepsis or ALI is incompletely defined, even though they appear to be the first cells of the lungs to be altered during ALI. The responses of lung microvascular endothelial cells lead to changes in the permeability of the vessels. This raises some important 
issues: i) whether Angptl4 is expressed in rat pulmonary microvascular endothelial cells (RPMVECs); and ii) effects of Angptl4 overexpression that occur during the LPS-induced injury of the pulmonary microvascular endothelium. This may be important in the modulation of endothelial function during LPS-induced ALI. Therefore, in this study, we used RPMVECs to determine whether Angptl4 overexpression attenuates the inflammatory response and whether the regulation of Angptl4 affects the modulation of endothelial function during LPS-induced ALI.

\section{Materials and methods}

Reagents. LPS from Escherichia coli and phalloidintetramethylrhodamine B isothiocyanate were purchased from Sigma-Aldrich (St. Louis, MO, USA). Polyclonal antisera against Angpt14, p-MEK1/2, p-AKT, Bax, caspase-8 and -9 were purchased from Santa Cruz Biotechnology, Inc. (Santa Cruz, CA, USA). The Angptl4 gene was purchased from Source BioScience (Nottingham, UK, BC078944). Extracellular matrix (ECM), fetal calf serum, penicillin and streptomycin were purchased from ScienCell Research Laboratories (Carlsbad, CA, USA). Plastic tissue culture flasks were from Costar (Cambridge, MA, USA).

Isolation of RPMVCs and primary cell culture. The isolation of microvascular endothelial cells was performed according to a modified method originally developed by Chen et al (21). Briefly, the fresh lungs isolated from the sacrificed rats were washed with $50 \mathrm{ml}$ serum-free DMEM. The pleura was discarded from the lung tissue and the outer edges of the lung lobe, which did not contain large blood vessels, cut off and minced in serum-free DMEM using scissors. The pellet was rinsed followed by the addition of DMEM containing $20 \%$ fetal calf serum, $100 \mathrm{U} / \mathrm{ml}$ of penicillin and $0.1 \mathrm{mg} / \mathrm{ml}$ streptomycin. The cells were incubated at $37^{\circ} \mathrm{C}$ in a $5 \% \mathrm{CO}_{2}$ incubator. After $60 \mathrm{~h}$, the residue lung tissues were removed and the cells were grown in plastic tissue culture flasks. The culture medium was replaced every 3 days and after reaching confluence, the cells were treated with a $0.25 \%$ solution of trypsin. The RMVECs were identified according to morphological and functional criteria. They were examined under an inverted microscope by phase-contrast microscopy.

Experimental design. The cells were randomly divided into the following groups: i) control (CON) group; ii) LPS group: cells were exposed to $100 \mathrm{ng} / \mathrm{ml}$ LPS and incubated for 6, 12 and $24 \mathrm{~h}$; iii) LPS + rosiglitazone (ROZ) group: cells were exposed to $100 \mathrm{ng} / \mathrm{ml} \mathrm{LPS}$ and $50 \mu \mathrm{g} / \mathrm{ml} \mathrm{ROZ}$ and incubated for 6, 12 and 24 h; iv) LPS + GW9662 group: cells were exposed to $100 \mathrm{ng} / \mathrm{ml}$ LPS and $50 \mu \mathrm{g} / \mathrm{ml} \mathrm{GW} 9662$ and incubated for 6, 12 and $24 \mathrm{~h}$; v) pcDNA3.1-eGFP group: cells were transfected with pcDNA3.1-eGFP and incubated for $48 \mathrm{~h}$; vi) pcDNA3.1-Angptl4-eGFP group: cells were transfected with pcDNA3.1-Angptl4-eGFP and incubated for 48 h; vii) LPS + pcDNA3.1-eGFP group: cells were transfected with pcDNA3.1-eGFP and incubated for $48 \mathrm{~h}$; they were then exposed to $100 \mathrm{ng} / \mathrm{ml}$ LPS and incubated for 6,12 and 24 h; viii) LPS + pcDNA3.1-Angptl4-eGFP group: cells were transfected with pcDNA3.1-Angptl4-eGFP and incubated for
$48 \mathrm{~h}$; they were then exposed to $100 \mathrm{ng} / \mathrm{ml}$ LPS and incubated for 6,12 and $24 \mathrm{~h}$.

Angptl4 gene transfection. Cells (3-5 generation) were used for transfection. The day before transfection, cells were seeded at approximately $5 \times 10^{5}$ cells/well in a $60-\mathrm{mm}$ dish with $2 \mathrm{ml}$ appropriate growth medium until the cells reached $40-80 \%$ confluence. The following day, $5 \mu \mathrm{g}$ pcDNA3.1-eGFP or pcDNA3.1-Angpt14-eGFP DNA were separately dissolved in TE buffer, $\mathrm{pH} 7-8$, with cell growth medium containing no serum, proteins or antibiotics to a total volume of $150 \mu \mathrm{l}$. The solution was mixed and centrifuged briefly to remove drops from the top of the tube. Subsequently, $30 \mu \mathrm{l}$ SuperFect transfection reagent (Qiagen, Hilden, Germany) were added to the DNA solution. The solution was then mixed by pipetting up and down 5 times and the samples were incubated for 5-10 min at room temperature to allow transfection complex formation. Subsequently, $1 \mathrm{ml}$ cell growth medium (containing serum and antibiotics) was added to the reaction tube containing the transfection complexes, after being washed once with PBS. The solution was then mixed by pipetting up and down twice and the total volume was immediately transferred to the cells in the $60-\mathrm{mm}$ dish. The cells were incubated with the transfection complexes for $2-3 \mathrm{~h}$ at $37^{\circ} \mathrm{C}$ in a $5 \% \mathrm{CO}_{2}$ incubator. The cells were transfected with the pcDNA3.1-eGFP or pcDNA3.1Angptl4-eGFP constructs and incubated for 24-48 h post-transfection to detect the levels of gene expression.

Determination of Angptl4 mRNA expression by real-time $P C R$. Total cellular RNA was extracted from the cells $48 \mathrm{~h}$ post-transfection using RNAiso Plus (Takara Bio, Inc., Shiga, Japan) according to the manufacturer's recommendations. The level of Angpt14 mRNA expression was quantified by real-time PCR using Thermo Scientific Maxima SYBRGreen/ROX q-PCR Master Mix (2X) (Fisher Scientific, Vilnius, Lithuania). RNA was solubilized in RNase-free water and quantified by measurement of the absorbance at $260 \mathrm{~nm}$. The potency was $220-280 \mathrm{ng} / \mu \mathrm{l}$ (the purity of RNA was assured by examining the OD 260/280 as 1.6/1.9). cDNA was synthesized using an iScript ${ }^{\mathrm{TM}} \mathrm{cDNA}$ synthesis kit and reverse transcription was then performed on a $1 \mu \mathrm{l}$ RNA sample by the addition of iScript reagents. Amplification and detection were performed using the Rotor Gene $3000^{\mathrm{TM}}$ sequence detection system (Corbett Research, Berkeley, CA, USA) starting with $500 \mathrm{ng}$ of cDNA. The primers and probes used were: Angptl4 forward, 5'-GCCGCTACTATCCACTAC-3' and reverse, 5'-CCTGTTGCTCTGACTGTT-3'; and $\beta$-actin forward, 5'-GGAGATTACTGCCCTGGCTCCTA-3' and reverse, 5'-GACTCATCGTACTCCTGCTTGCTG-3'. $\beta$-actin was used as an internal control. For relative quantification, the copy ratios of Angptl $/ / \beta$-actin were calculated and used as an indication of the relative expression levels.

Western blot analysis. After the cell monolayer reached confluence, the RPMVECs were washed with ice-cold PBS and were then resuspended at $1 \times 10^{6}$ cells $/ 100 \mu \mathrm{l}$ in ice-cold lysis buffer $(50 \mathrm{mmol} / \mathrm{l}$ Tris- $\mathrm{HCl}, \mathrm{pH} 8.0,150 \mathrm{mmol} / \mathrm{l} \mathrm{NaCl}$, $1 \%$ Triton $\mathrm{X}-100,1 \mathrm{mmol} / \mathrm{l}$ phenylmethyl sulfonyl fluoride, $0.02 \%$ sodium azide and $1 \mu \mathrm{g} / \mathrm{ml}$ aprotinin) and the adherent cells were scraped off the plate into $100 \mu 1$ lysis buffer $/ 50 \mathrm{~cm}^{2}$ 
culture plate surface. The cell lysates were placed on ice for $20 \mathrm{~min}$ and then centrifuged at $12,000 \mathrm{x} \mathrm{g}$ for $10 \mathrm{~min}$ at $4^{\circ} \mathrm{C}$. The post-mitochondrial supernatant fraction was removed and stored in aliquots at $-20^{\circ} \mathrm{C}$. The protein concentration of the samples was estimated using an ultraviolet spectrophotometer (Perkin-Elmer, Norwalk, CT, USA). Cell lysates were separated by sodium dodecyl sulfate-10\% polyacrylamide gel electrophoresis (SDS-PAGE). Briefly, after the SDS-PAGE gels were run, they were transferred onto polyvinylidene difluoride (PVDF) membranes using a semi-dry blot system (Trans-Blot SD Semi-dry Transfer Cell; Bio-Rad, Richmond, CA, USA). The membrane was blocked with blocking buffer ( $0.4 \%$ gelatin) for $1 \mathrm{~h}$ at $37^{\circ} \mathrm{C}$ and then probed with primary antibodies. Dilutions for primary antibodies were as follows: anti-rat p-MEK1/2 antibody (200 $\mu \mathrm{g} / \mathrm{ml} ; 1: 400)$, anti-rat Bax antibody (200 $\mu \mathrm{g} / \mathrm{ml} ; 1: 400)$, anti-rat p-AKT (T450) antibody (200 $\mu \mathrm{g} / \mathrm{ml} ; 1: 400$, all from Santa Cruz Biotechnology, Inc.), anti-rat AKT antibody $(200 \mu \mathrm{g} / \mathrm{ml} ; 1: 400$, Bioworld Technology, Minneapolis, MN, USA), anti-rat casapase- 8 and -9 antibody $(200 \mu \mathrm{g} / \mathrm{ml} ; 1: 400)$, rabbit polyclonal anti-rat Angptl4 antibody $(200 \mu \mathrm{g} / \mathrm{ml} ; 1: 300)$ and anti-mouse $\beta$-actin antibody $(200 \mu \mathrm{g} / \mathrm{ml} ; 1: 400$, all from Santa Cruz Biotechnology, Inc.), overnight at $4^{\circ} \mathrm{C}$. The membrane was washed with PBST (PBS containing 0.5\% Tween-20) and then incubated with horseradish peroxidase-conjugated goat anti-rabbit or rabbit anti-goat, rabbit anti-mouse secondary antibodies $(500 \mu \mathrm{g} / \mathrm{ml}$; $1: 10,000)$ at $37^{\circ} \mathrm{C}$ for $1 \mathrm{~h}$. Following repeated washes with PBST, the antibody-antigen complexes were detected with ECL reagent (Immobilon ${ }^{\mathrm{TM}}$ Western Chemiluminescent HRP Substrate; Millipore, Billerica, MA, USA) and exposed to X-OMAT BT film (Kodak). Films were scanned and the optical density (OD) of each band was detected using the ChemiDoc $^{\mathrm{TM}}$ XRS+ imaging system (Bio-Rad). The molecular weights of the proteins were estimated by comparison with the positions of the standard.

Cell viability assay. The viability of the cultured cells was determined by MTT assay. The RPMVECs $\left(10 \times 10^{4}\right.$ cells/well $)$ were plated in 24 -well plates and incubated at $37^{\circ} \mathrm{C}$ in a $5 \% \mathrm{CO}_{2}$ incubator. The cells were then divided into the normal, LPS, LPS + ROZ, LPS + GW9662, pcDNA3.1-eGFP, pcDNA3.1-Angpt14-eGFP, LPS + pcDNA3.1-eGFP and LPS + pcDNA3.1-Angpt14-eGFP group and incubated for different periods of time (6,12 and $24 \mathrm{~h})$. Subsequently, $100 \mu \mathrm{l}$ of MTT $(5 \mathrm{mg} / \mathrm{ml})$ were added to each well for an additional $4 \mathrm{~h}$ at $37^{\circ} \mathrm{C}$. The supernatant was removed and DMSO was added to dissolve the formazan crystals. The optical absorbance was measured at $540 \mathrm{~nm}$.

Enzyme-linked immunosorbent assay (ELISA). ELISA was performed to quantify the concentration of TNF- $\alpha$ in the culture medium using commercially available kits. The TNF- $\alpha$ kit was purchased from R\&D Systems (Minneapolis, MN, USA).

Immunofluorescence. The RPMVECs were washed once with PBS and fixed in 3.7\% formaldehyde solution in PBS for $10 \mathrm{~min}$. They were then washed extensively with PBS. They were dehydrated with aceton and then permeabilized by incubation in PBS containing $0.1 \%$ Triton X-100. After being washed with PBS; the cells were stained with $50 \mu \mathrm{g} / \mathrm{ml}$ fluorescent phalloidin conjugate solution in PBS for $40 \mathrm{~min}$ at room temperature. They were then washed several times with PBS to remove unbound phalloidin conjugate and incubated for $10 \mathrm{~min}$ with DAPI. They were then washed extensively with PBS. The stained cells were then examined under a Leica confocal laser scanning microscope (Leica Microsystems, Mannheim, Germany).

Statistical analysis. All data are expressed as the means \pm SD and were analyzed statistically using one-way ANOVA followed by the Newman-Keuls test. A P-value $<0.05$ was considered to indicate a statistically significant difference. All statistical analyses were performed using Graph Pad Prism 5 software.

\section{Results}

Characteristics of RPMVECs. The cells grew initially as capillary-like structures and assumed the typical cobblestone morphology of endothelial cells at confluence (Fig. 1A). These cells were characterized as endothelial cells by CD31 antigen expression. Using immunofluorescence, the positive expression of CD31 antigen in the RPMVECs was demonstrated by green particles in the cytoplasm (Fig. 1B). The cells displayed negative staining by BSA (Fig. 1C). The cells were transfected with the pcDNA3.1-eGFP or the pcDNA3.1-eGFP-Angpt14 vector and incubated for $48 \mathrm{~h}$. (Fig. 1E)

Effect of LPS on Angptl4 mRNA and protein expression in RPMVECs. The RPMVECs were cultured and exposed to LPS for $24 \mathrm{~h}$ and 2 groups of cells were administered ROZ or GW9662. The protein expression of Angptl4 was determined by western blot analysis using Angpt14 antibodies as described in Materials and methods. The mRNA expression of Angptl4 was determined by real-time PCR (Fig. 2A). The mRNA and protein expression of Angptl4 was slightly increased following exposure to LPS. ROZ significantly increased the expression of Angpt14 and GW9662 had the opposite effect. These results indicate that LPS induces a slight increase in the expression of Angptl4 in the PMVECs and ROZ markedly induces its expression.

Effect of LPS on upregulation of Angptl4 $m R N A$ and protein expression in RPMVECs. The RPMVECs were cultured and transfected with the pcDNA3.1-eGFP or the pcDNA3.1-eGFP-Angpt14 vector and then stimulated with LPS (Fig. 2B). We found that the mRNA levels increased by almost 2 -fold compared with the blank group, whereas the levels tripled following treatment with ROZ and LPS. The protein levels were also altered.

Anti-apoptotic effect of the overexpression of Angptl4 on RPMVECs exposed to LPS. RPMVECs administered with $\mathrm{ROZ}$ and the transfected cells were cultured and exposed to LPS for $24 \mathrm{~h}$. We then detected the expression levels of the pro-apoptotic factors, Bax and casapase- 8 and -9 by western blot analysis (Fig. 3). Our results revealed that the expression of these factors was markedly decreased with the upregulation of Angpt14. Of note, an opposite effect occurred after transfection. This may be due to the secretion of Angpt14 protein as a protective factor during acute injury. 
A

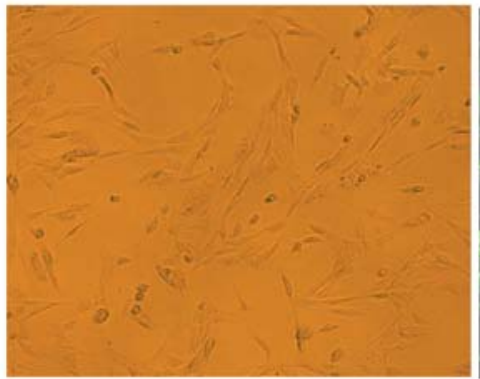

D

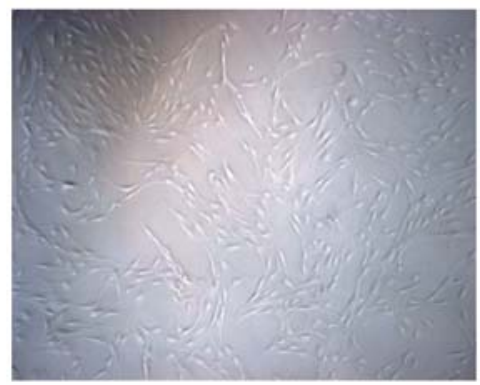

B

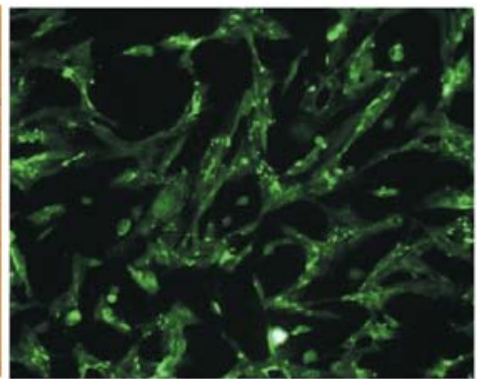

(2)
C

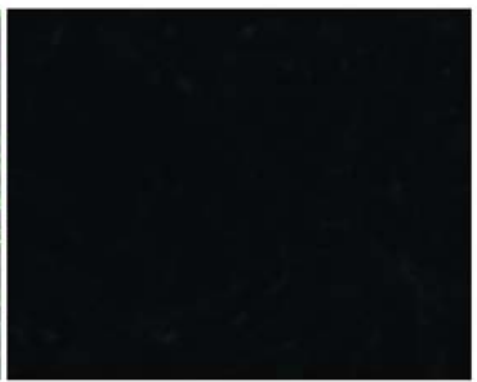

$\mathbf{E}$

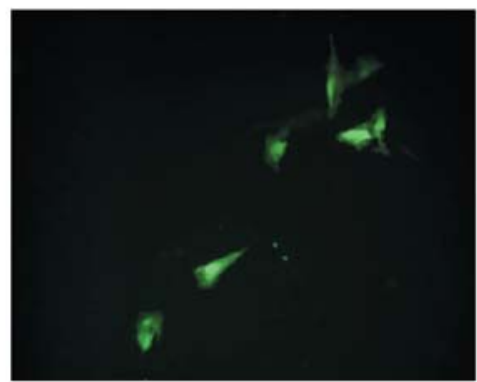

Figure 1. (A and D) Cultured normal rat pulmonary microvascular endothelial cells (RPMVECs). (B) Positive group: RPMVECs were incubated with rabbit anti-rat CD31 antibody and FITC-labeled goat anti-rabbit IgG. (C) Negative group with 5\% BSA instead of primary antibody incubation. (E) RPMVECs transfected with pcDNA3.1-eGFP and incubated for $48 \mathrm{~h}$ as the blank control group.

A

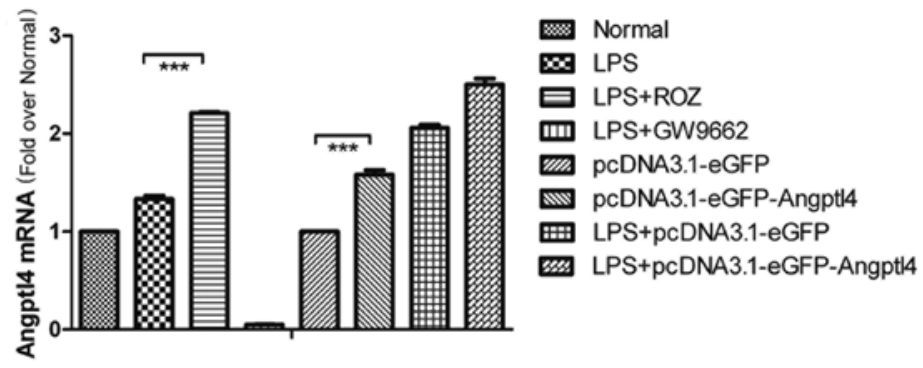

B
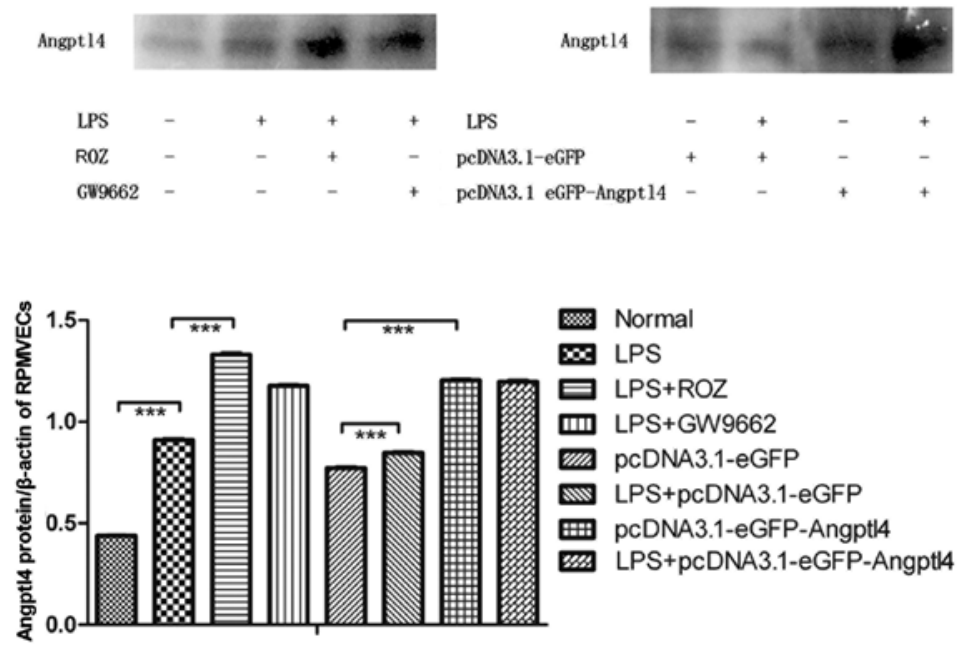

Figure 2. The expression of Angpt14 mRNA was determined by real-time PCR. (A) The results showed that the expression of Angpt14 in the pcDNA3.1-eGFPAngpt14-transfected group was markedly increased compared with the control group $\left(^{* * *} \mathrm{P}<0.01\right)$. (B) The protein expression was also altered; however, the protein expression may be influenced by other factors after DNA transcription; there was no difference in protein expression between the LPS-pcDNA3.1eGFP-Angpt14 group and the pcDNA3.1-eGFP-Angptl4 group $(\mathrm{P}>0.05)$. The effects of rosiglitazone [(ROZ) group] were similar to those induced by pcDNA3.1-eGFP-Angpt14 ( $\mathrm{P}>0.05)$ and differed from the lipopolysaccharide (LPS) group $\left.{ }^{* * *} \mathrm{P}<0.01\right)$. 

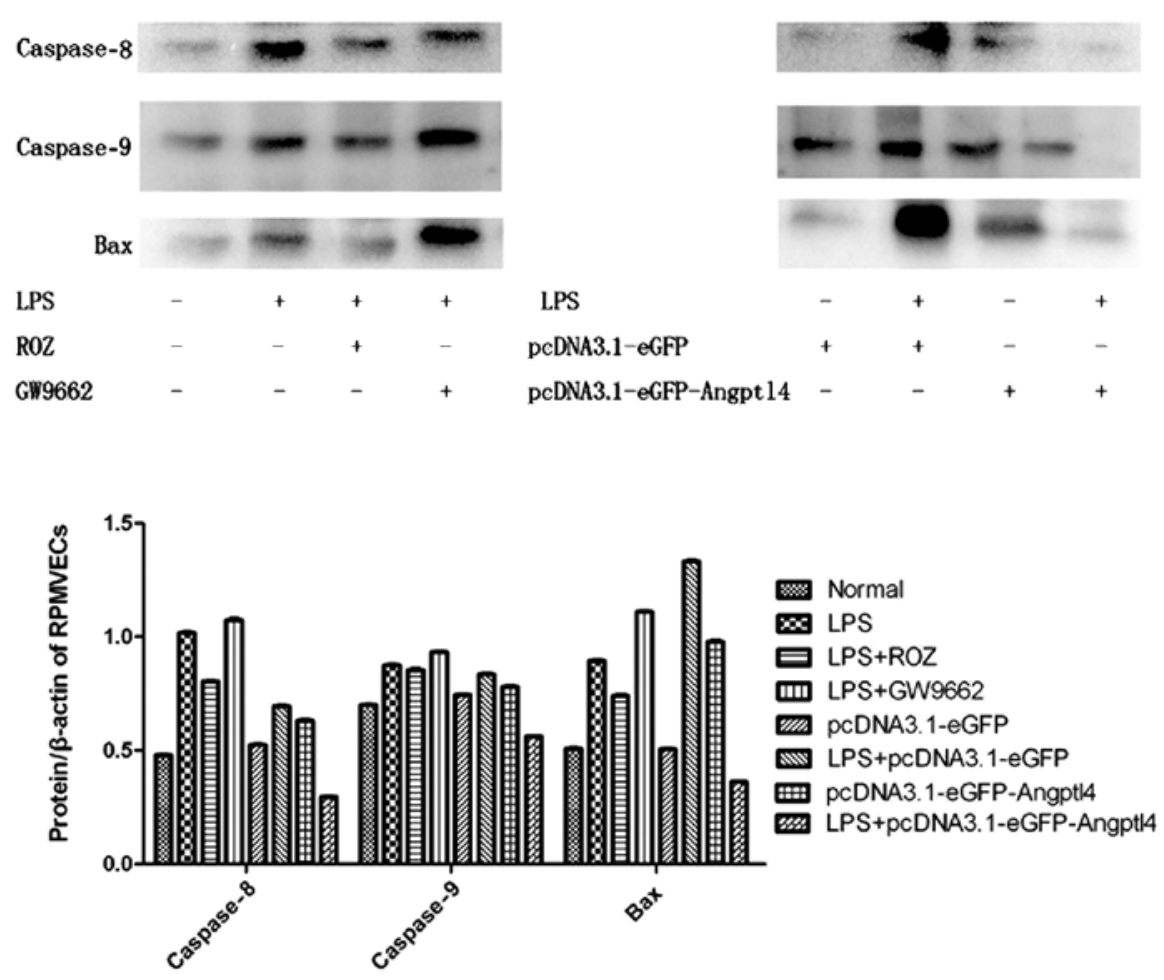

Figure 3. The mRNA and protein expression of the pro-apoptotic factors, Bax, caspase- 8 and -9 , was markedly decreased in the rosiglitazone (ROZ) and LPS-pcDNA3.1-eGFP-Angpt14 group compared with the lipopolysaccharide (LPS) group ( $\mathrm{P}<0.01)$. The expression was higher in the transfected groups compared with the control group; this may be due to the harmful effects of transfection.

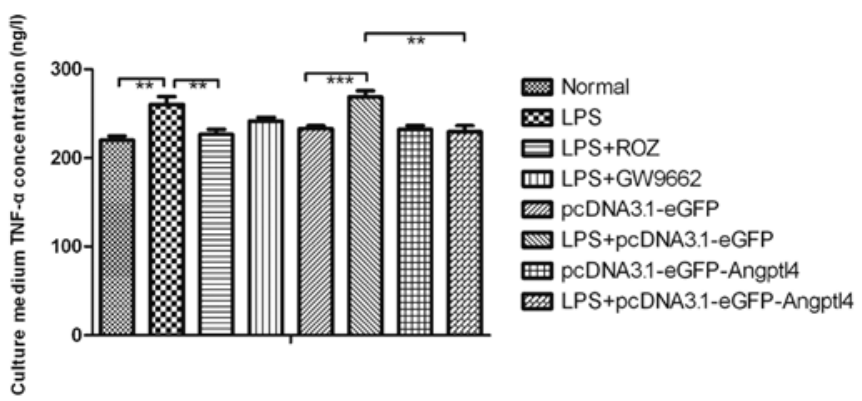

Figure 4. TNF- $\alpha$ concentration in the cell culture medium was examined by ELISA. Data are presented as the means $\pm \mathrm{SD}$. ${ }^{* *} \mathrm{P}<0.05$, normal vs. lipopolysaccharide (LPS) group. ${ }^{* * *} \mathrm{P}<0.01, \mathrm{ROZ}$ vs. LPS + pcDNA3.1-eGFP group. ${ }^{* * * *} \mathrm{P}<0.01$, LPS + pcDNA3.1-eGFP group vs. the pcDNA3.1-eGFP-Angpt14 group.

Measurement of TNF- $\alpha$ concentration in culture medium by ELISA. To determine whether the overexpression of Angptl4 affects angiogenic and inflammatory molecules, such as TNF- $\alpha$, ELISA was carried out. The TNF- $\alpha$ concentration in the cell culture medium in the LPS group was markedly increased compared with the CON group (Fig. 4, $\mathrm{P}<0.01$ ). However, the decrease in the TNF- $\alpha$ concentration in the ROZ group and the group transfected with Angptl4 and treated with LPS was significant $(\mathrm{P}<0.01)$. These results suggest that the improved anti-inflammatory functions may partly contribute to the beneficial metabolic effects of Angpt14. These data demonstrate that the secretion of Angpt14 in serum may influence the TNF- $\alpha$ concentration; however, the exact mechanisms involved require further investigation.
Angptl4 overexpression protects RPMVECs against vascular permeability induced by LPS. Previously, it was shown that the stimulation of RPMVECs with LPS results in cytoskeletal rearrangement, which can destroy the F-actin cytoskeletan $(22,23)$. Another study reported that the inhibition of the phosphorylation of ERK $1 / 2$ attenuates the polymerization of F-actin induced by LPS (24). In the current study, the overexpression of Angpt14 was used to examine the hypothesis that ERK1/2 activation is involved in LPS-induced actin cytoskeletal rearrangement. As shown in Fig. 5, we found that the p-MEK1/2 protein expression was markedly suppressed in the LPS-pcDNA3.1-Angpt14-eGFP group $(\mathrm{P}<0.01)$. As shown in Fig. 6, the RPMVECs exhibited a well organized actin cytoskeleton with F-actin fibers crossing the body of the cells and forming a dense filamentous network. The cells exposed to LPS showed a significant reduction in the number of stress fibers and a different pattern of these stress fibers, i.e., they were distributed in the periphery of the cells (Fig. 6B). The RPMVECs pre-treated with ROZ exhibited a morphology and actin stress fibers similar to those of the control cells. Importantly, as shown in Fig. 6D, transfection with Angptl4 blocked the effects of LPS on the actin cytoskeleton. These results indicate that the overexpression of Angptl4 inhibits ERK1/2 activation and plays a key role in actin cytoskeletal changes in RPMVECs induced by LPS.

Effect of upregulation of Angptl4 on cell viability. The effect of the upregulation of Angpt14 on cell viability was dose- and time-dependent (Fig. 7). The absorption values significantly increased following treatment with $\mathrm{ROZ}(50 \mu \mathrm{g} / \mathrm{ml})$ and transfection with Angptl4 for 12 and $24 \mathrm{~h}(\mathrm{P}<0.05)$. The results revealed that the upregulation of Angptl4 improved the cell 

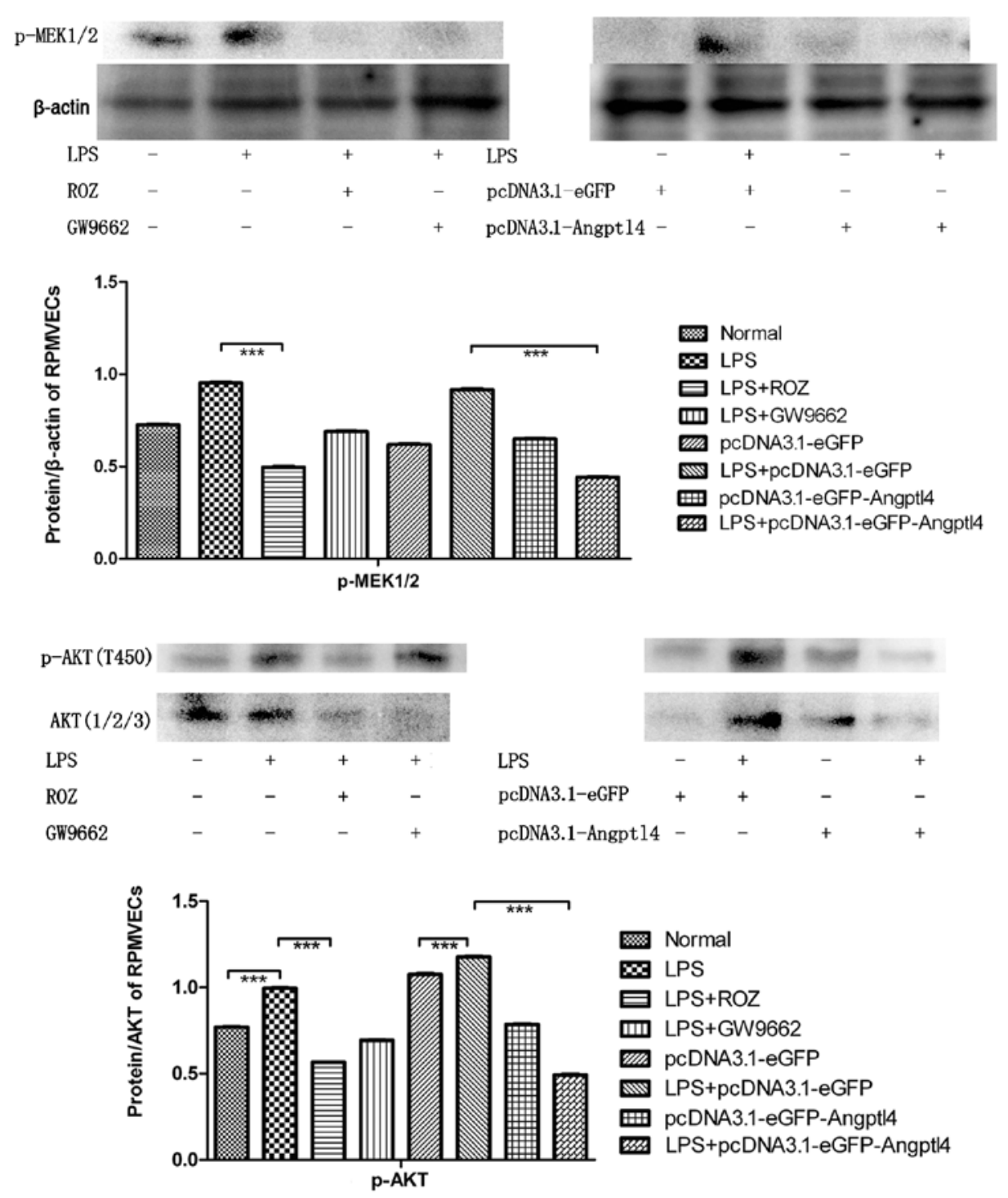

Figure 5. Protein expression of p-AKT/AKT and p-MEK1/2 was decreased following the administration of rosiglitazone (ROZ) and pcDNA3.1-Angpt14-eGFP transfection $\left({ }^{* * *} \mathrm{P}<0.01\right)$. We deduced that the overexpression of angiopoietin-like 4 (Angptl4) protects pulmonary microvascular endothelial cells (RPMVECs) by inhibiting the MEK-Raf-MAPK cascade, thus inhibiting inflammation.

viability of the RPMVECs exposed to LPS following treatment with ROZ and transfection with Angptl4 for $24 \mathrm{~h}$. Therefore, we selected the time point of $24 \mathrm{~h}$ to observe the effects of ROZ on cell apoptosis.

\section{Discussion}

The results of the present study demonstrate the effect of Angptl4 expression on RPMVECs during an acute inflammatory stroke. This process needs to be explored further. The pulmonary endothelium serves as a semi-selective barrier between the plasma and interstitium of circulatory cells, macromolecules and bioactive agents. The maintenance of this semi-selective barrier represents an important physiological process for vessel wall homeostasis and lung function. Injury to the endothelium results in barrier dysfunction with exudation of proteins and fluid within the interstitial tissue and alveolar space that contributes to edema in lung injury.

LPS, a major component of Gram-negative bacterial outer membranes, is an endotoxin that is believed to be the main initiator of microcirculatory abnormalities in septic ALI. The administration of LPS in various models has been shown to induce profound vascular leakage in vivo (25) and to increase the permeability of cultured endothelial cells. Studies have shown that in cultured endothelial cells, an LPS-induced increase in endothelial permeability occurs through several pathways, such as endothelial contraction caused by the RhoA-dependent increase in myosin light chain kinase (MLC) phosphorylation (26), reorganization of actin filaments, protein tyrosine phosphorylation (27), etc.. We found that the F-actin cytoskeleton in the RPMVECs in the LPS group was destroyed and that the cell viability was markedly decreased.

In the present study, we aimed to determine the role of Angptl4 in inflammatory responses. Angptl4 is a $50 \mathrm{kDa}$ protein that belongs to the angiopoietin-like family, all of which have a secondary structural organization similar to angiopoietins, including a $\mathrm{NH}_{2}$-terminal coiled domain and a $\mathrm{COOH}$-terminal fibrinogen-like domain $(28,29)$. However, Angptl4 does not bind to either the Tie1 or Tie2 angiopoietin receptors (30). Thus, it is currently considered an orphan 
A

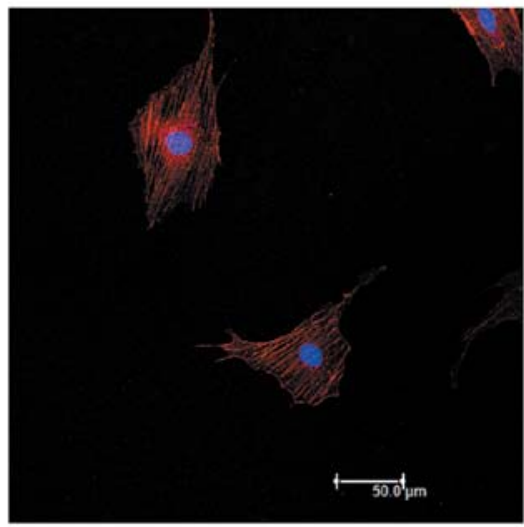

C

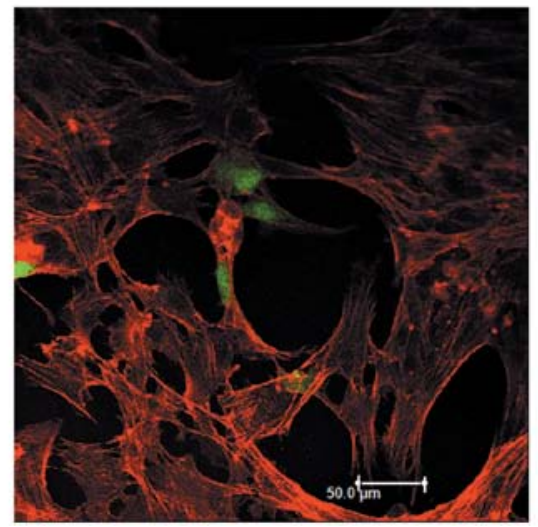

B

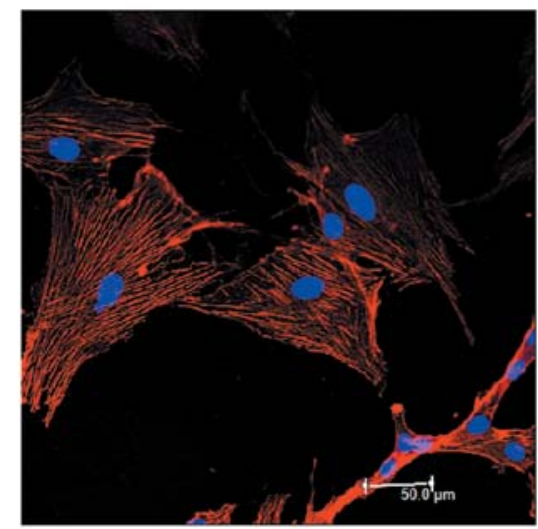

D

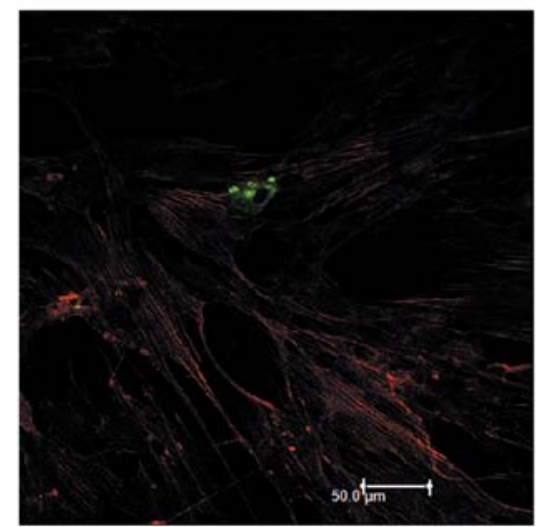

Figure 6. Rat pulmonary microvascular endothelial cells (RPMVECs) were incubated with phalloidin-tetramethylrhodamine B isothiocyanate and then examined under a confocal microscope. (A) Normal group. (B) LPS group. (C) LPS + pcDNA3.1-eGFP group. (D) LPS + pcDNA3.1-Angpt14-eGFP group.

A

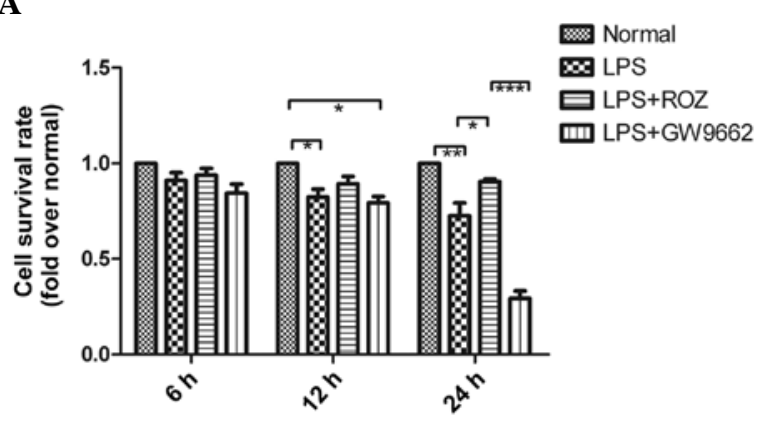

B

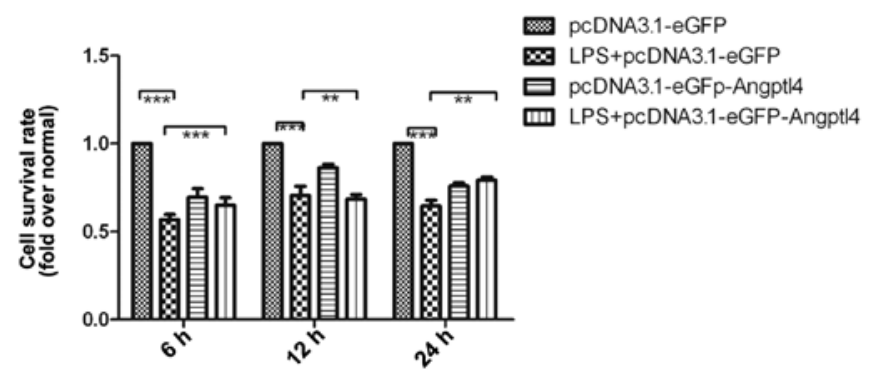

Figure 7. (A) The viability of the cultured rat pulmonary microvascular endothelial cells (RPMVECs) was determined by MTT assay. The results revealed that the administration of rosiglitazone (ROZ) cells prolonged survival in the cells exposed to lipopolysaccharide (LPS) (P<0.01). (B) The viability of cultured RPMVECs was determined by MTT assay. The results revealed that transfection with LPS-eGFP-Angptl4 prolonged survival compared with the blank control (P<0.01).

ligand whose functions differ from those of Angptl1 and Angpt12. Over the last few years, a number of experimental studies have further demonstrated that Angptl4 is involved in key events of tumor growth $(5,31)$. It has been suggested that Angpt14 inhibits VEGF-induced vascular leaks and neoangiogenesis in tumors, while others have shown that Angptl4 hijacks integrin-mediated signaling to maintain an elevated, oncogenic $\mathrm{O}_{2}: \mathrm{H}_{2} \mathrm{O}_{2}$ ratio and therefore, confers anoikis resistance to tumor cells, suggesting that Angptl4 is an important player in redox-mediated cancer progression (5).

A previous study showed that Angptl4 is a positive acute phase protein whose expression is increased in the liver, heart, muscle and adipose tissue during the acute phase response (32). In this study, we demonstrate that Angptl4 expression increases in RPMVECs administered with LPS during ALI. The mechanism accounting for the increase in Angptl4 expression during the acute phase response is unknown. Angptl4 expression is stimulated by PPARs (33), although previous studies have shown it is unlikely that PPAR activation accounts for the observed effects (34). The present study confirmed the increased expression of Angptl4 at the mRNA and protein level during the early stages of the LPS stimulation of RPMVECs, which increased following the administration of ROZ and transfection with pcDNA3.1-eGFP-Angpt14.

The molecular mechanisms that underlie the observed functional response heterogeneity to Angptl4 in pulmonary macrovascular cells are unknown but presumably involve the differential activation of signals downstream of Angptl4. 
Since Angpt14 is highly similar to angiopoietins structurally, it is not surprising that human Angpt14, similar to Ang1, has anti-apoptotic effects on endothelial cells, which can lead to the stabilization of newly formed blood vessels. Consistent with this, human Angptl4 has been shown to promote the survival of endothelial cells and blood vessel formation in in vivo experimental systems. Of note, Yang et al (35) showed that C-Angptl4 attenuates the bFGF-induced phosphorylation of ERK1/2 MAP kinase, but not that of Akt and p38 MAP kinase. In this study, immunofluorescence staining revealed that transfection with Angptl4 and treatment with ROZ and LPS inhibited p-MEK1/2 expression. This suggests the Raf/MEK/ERK cascade inhibited phosphorylated ERK polymerization with F-actin, inhibiting the depolymerization and decreased density of central F-actin in the PMVECs. It stabilized the formulation and protected the cytoskeleton, while the permeability of RPMVECs was decreased significantly. A previous study suggested that Angptl4 prevents metastasis by inhibiting vascular leaks (36). We confer that the overexpression Angpt14 protects the cytoskeleton of RPMVECs and decreases pro-inflammatory cytokine leaks.

Previous studies have suggested the potential pro-angiogenic activity of Angpt14, and data from several independent laboratories have also demonstrated that Angptl4 is a potent anti-angiogenic factor $(34,37)$. Kim et al (30) showed that Angptl4 protects endothelial cells from apoptosis through an endocrine action, whereas Oike et al (29) showed that Angptl4 inhibits VEGF-induced vascular leaks and neoangiogenesis. In several studies, VEGF has been shown to induce vascular permeability and lead to neutrophil infiltration, even tissue edema. However, Angptl4 has been shown to inhibit the VEGF-induced phosphorylation of ERK1/2, attributed to its specific suppression of the ERK1/2 MAP kinase pathway $(35,38)$.

In addition, we found that p-Akt (T450) decreased following the induction of the overexpression of Angptl4 in the cells stimulating with LPS. Nevertheless, there is a contradicting result in vitro; the transfection of Angptl4 may induce apoptopsis, but may inhibit apoptopsis following exposure to LPS, which decreased Bax and caspase-8, and -9 protein expression in this study. The reasons for these conflicting results and the underlying mechanism of Angptl4 activity in the inflammatory response, may be that p-AKT/AKT downregulation may have inactivated the phosphorylation NF- $\kappa B$ and inhibited the downstream production of inflammatory cytokines (39), such as TNF- $\alpha$. TNF- $\alpha$ is a pro-inflammatory mediator that promotes the adhesion of leukocytes to the endothelium and plays a vital role in the pathogenesis of severe acute pancreatitis (SAP) (40). The increase in tissue and serum TNF- $\alpha$ concentrations correlates directly with the severity of pancreatic damage and inflammation in ALI (41). It can in turn damage the vascular barrier, promoting leaks. As is already known, TNF- $\alpha$ is mediated by a number of signaling pathways, such as the ERK1/2-MAPK and TPK-Ras-MAPK pathways. The decrease in the TNF- $\alpha$ concentration maybe be associated with the inhibition of the Raf/MEK/ERK cascade. In this study, we found that the TNF- $\alpha$ concentration was markedly decreased in the ROZ and pcDNA3.1-eGFP-Angptl4 groups, which suggests that the overexpression of Angpt14 is associated with the anti-inflammatory response.
In conclusion, the data from the present study demonstrate that Angptl4 is a protective secreted protein that acts downstream of other signaling events. Our results provide novel evidence demonstrating that the possible anti-inflammatory mechanisms of Angptl4 involve the protection of the cytoskeleton by inhibiting cell contraction and decreasing the expression of inflammatory cytokines. Further studies are required to fully elucidate the signaling events underlying the anti-angiogenic properties and anti-apoptotic activity of Angpt14.

\section{Ackowledgements}

This study was supported by The National Natural Science Foundation of China (FNSFC_81173452). We completed this study at the Laboratory of the First Affiliated Hospital of Dalian Medical University and Dalian Center Hospital. The authors thank HaiLong Li, Jun Ji and DongShang for their helpful discussions.

\section{References}

1. Ge H, Yang G, Yu X, Pourbahrami T and Li C: Oligomerization state-dependent hyperlipidemic effect of angiopoietin-like protein 4. J Lipid Res 45: 2071-2079, 2004.

2. $\mathrm{Xu} \mathrm{A}$, Lam MC, Chan KW, et al: Angiopoietin-like protein 4 decreases blood glucose and improves glucose tolerance but induces hyperlipidemia and hepatic steatosis in mice. Proc Natl Acad Sci USA 102: 6086-6091, 2005.

3. Sukonina V, Lookene A, Olivecrona T and Olivecrona G: Angiopoietin-like protein 4 converts lipoprotein lipase to inactive monomers and modulates lipase activity in adipose tissue. Proc Natl Acad Sci USA 103: 17450-17455, 2006.

4. Mandard S, Zandbergen F, van Straten E, Wahli W, Kuipers F, Muller $M$ and Kersten $S$ : The fasting-induced adipose factor/angiopoietin-like protein 4 is physically associated with lipoproteins and governs plasma lipid levels and adiposity. J Biol Chem 281: 934-944, 2006.

5. Zhu P, Tan MJ, Huang RL, et al: Angiopoietin-like 4 protein elevates the prosurvival intracellular $\mathrm{O}_{2}(-): \mathrm{H}_{2} \mathrm{O}_{2}$ ratio and confers anoikis resistance to tumors. Cancer Cell 19: 401-415, 2011.

6. Kersten S: Regulation of lipid metabolism via angiopoietin-like proteins. Biochem Soc Trans 33:1059-1062, 2005.

7. Mandard S, Zandbergen F, Tan NS, et al: The direct peroxisome proliferator-activated receptor target fasting-induced adipose factor (FIAF/PGAR/ANGPTL4) is present in blood plasma as a truncated protein that is increased by fenofibrate treatment. J Biol Chem 279: 34411-34420, 2004.

8. Koliwad SK, Kuo T, Shipp LE, et al: Angiopoietin-like 4 (ANGPTL4, fasting-induced adipose factor) is a direct glucocorticoid receptor target and participates in glucocorticoid-regulated triglyceride metabolism. J Biol Chem 284: 25593-25601, 2009.

9. Padua D, Zhang XH, Wang Q, et al: TGF beta primes breast tumors for lung metastasis seeding through angiopoietin-like 4 . Cell 133: 66-77, 2008.

10. Belanger AJ, Lu H, Date T, et al: Hypoxia up-regulates expression of peroxisome proliferator-activated receptor gamma angiopoietin-related gene (PGAR) in cardiomyocytes: role of hypoxia inducible factor 1alpha. J Mol Cell Cardiol 34: 765-774, 2002

11. Liu F, Li W, Pauluhn J, Trubel H and Wang C: Lipopolysaccharide-induced acute lung injury in rats: comparative assessment of intratracheal instillation and aerosol inhalation. Toxicology 304: 158-166, 2013.

12. Feingold KR, Shigenaga JK, Cross AS, Moser A and Grunfeld C: Angiopoietin like protein 4 expression is decreased in activated macrophages. Biochem Biophys Res Commun 421: 612-615, 2012.

13. Ichikawa $\mathrm{H}$, Naito $\mathrm{Y}$, Takagi $\mathrm{T}$, et al: A specific peroxisome proliferator-activated receptor-gamma (PPAR-gamma) ligand, pioglitazone, ameliorates gastric mucosal damage induced by ischemia and reperfusion in rats. Redox Rep 7: 343-346, 2002. 
14. Konturek PC, Brzozowski T, Kania J, et al: Pioglitazone, a specific ligand of the peroxisome proliferator-activated receptor gamma reduces gastric mucosal injury induced by ischaemia/reperfusion in rat. Scand J Gastroenterol 38: 468-476, 2003.

15. Villegas I, Martin AR, Toma W and de la Lastra CA: Rosiglitazone, an agonist of peroxisome proliferator-activated receptor gamma, protects against gastric ischemia-reperfusion damage in rats: role of oxygen free radicals generation. Eur J Pharmacol 505: 195-203, 2004.

16. Wada K, Nakajima A, Takahashi $\mathrm{H}$, et al: Protective effect of endogenous PPARgamma against acute gastric mucosal lesions associated with ischemia-reperfusion. Am J Physiol Gastrointest Liver Physiol 287: G452-G458, 2004.

17. Takagi T, Naito Y, Ichikawa H, et al: A PPAR-gamma ligand, 15-deoxy-Delta12,14-prostaglandin $\mathrm{J}(2)$, inhibited gastric mucosal injury induced by ischemia-reperfusion in rats. Redox Rep 9: 376-381, 2004.

18. Naito Y, Takagi T, Matsuyama K, Yoshida N and Yoshikawa T: Pioglitazone, a specific PPAR-gamma ligand, inhibits aspirin-induced gastric mucosal injury in rats. Aliment Pharmacol Ther 15: 865-873, 2001.

19. Slomiany A, Nishikawa $\mathrm{H}$ and Slomiany BL: Screening and modulation of extracellular signals by mucous barrier. Serum glycosylphosphatidylinositol phospholipase D (GPI-PLD) releases protective mucous barrier from oral mucosa. J Physiol Pharmacol 53: 21-38, 2002.

20. Lappas M, Permezel M and Rice GE: 15-Deoxy-Delta(12,14)prostaglandin $\mathrm{J}(2)$ and troglitazone regulation of the release of phospholipid metabolites, inflammatory cytokines and proteases from human gestational tissues. Placenta 27: 1060-1072, 2006.

21. Chen SF, Fei X and Li SH: A new simple method for isolation of microvascular endothelial cells avoiding both chemical and mechanical injuries. Microvasc Res 50: 119-128, 1995.

22 Cheng C, Liu H, Ge H, et al: Lipopolysaccharide induces expression of SSeCKS in rat lung microvascular endothelial cell. Mol Cell Biochem 305: 1-8, 2007.

23. Zhang $H$ and Sun GY: LPS induces permeability injury in lung microvascular endothelium via AT(1) receptor. Arch Biochem Biophys 441: 75-83, 2005.

24. Adkison JB, Miller GT, Weber DS, et al: Differential responses of pulmonary endothelial phenotypes to cyclical stretch. Microvasc Res 71: 175-184, 2006.

25. Gao G, Kapushoc ST, Simpson AM, Thiemann OH and Simpson L: Guide RNAs of the recently isolated LEM125 strain of Leishmania tarentolae: an unexpected complexity. RNA 7: 1335-1347, 2001.

26. Essler M, Staddon JM, Weber PC and Aepfelbacher M: Cyclic AMP blocks bacterial lipopolysaccharide-induced myosin light chain phosphorylation in endothelial cells through inhibition of Rho/Rho kinase signaling. J Immunol 164: 6543-6549, 2000.
27. Harhaj NS and Antonetti DA: Regulation of tight junctions and loss of barrier function in pathophysiology. Int $\mathrm{J}$ Biochem Cell Biol 36: 1206-1237, 2004

28. Koishi R, Ando Y, Ono M, et al: Angptl3 regulates lipid metabolism in mice. Nat Genet 30: 151-157, 2002.

29. Oike Y, Yasunaga K, Ito Y, et al: Angiopoietin-related growth factor (AGF) promotes epidermal proliferation, remodeling, and regeneration. Proc Natl Acad Sci USA 100: 9494-9499, 2003.

30. Kim I, Kim HG, Kim H, et al: Hepatic expression, synthesis and secretion of a novel fibrinogen/angiopoietin-related protein that prevents endothelial-cell apoptosis. Biochem J 346: 603-610, 2000.

31. Brunckhorst MK, Wang H, Lu R, et al: Angiopoietin-4 promotes glioblastoma progression by enhancing tumor cell viability and angiogenesis. Cancer Res 70: 7283-7293, 2010.

32. Lu B, Moser A, Shigenaga JK, Grunfeld C and Feingold KR: The acute phase response stimulates the expression of angiopoietin like protein 4. Biochem Biophys Res Commun 391: 1737-1741, 2010.

33. Hermann LM, Pinkerton M, Jennings K, et al: Angiopoietinlike-4 is a potential angiogenic mediator in arthritis. Clin Immunol 115: 93-101, 2005.

34. Cazes A, Galaup A, Chomel C et al: Extracellular matrix-bound angiopoietin-like 4 inhibits endothelial cell adhesion, migration, and sprouting and alters actin cytoskeleton. Circ Res 99: 1207-1215, 2006.

35. Yang YH, Wang Y, Lam KS, et al: Suppression of the Raf/MEK/ ERK signaling cascade and inhibition of angiogenesis by the carboxyl terminus of angiopoietin-like protein 4 . Arterioscler Thromb Vasc Biol 28: 835-840, 2008.

36. Galaup A, Cazes A, Le Jan S, et al: Angiopoietin-like 4 prevents metastasis through inhibition of vascular permeability and tumor cell motility and invasiveness. Proc Natl Acad Sci USA 103: 18721-18726, 2006.

37. Li KQ, Li WL, Peng SY, et al: Anti-tumor effect of recombinant retroviral vector-mediated human ANGPTL4 gene transfection. Chin Med J (Engl) 117: 1364-1369, 2004.

38. Dhillon AS and Kolch W: Untying the regulation of the Raf-1 kinase. Arch Biochem Biophys 404: 3-9, 2002.

39. Wu F, Wang H, Li J, Liang J and Ma S: Homoplantaginin modulates insulin sensitivity in endothelial cells by inhibiting inflammation. Biol Pharm Bull 35: 1171-1177, 2012.

40. Masamune A, Watanabe T, Kikuta K and Shimosegawa T: Roles of pancreatic stellate cells in pancreatic inflammation and fibrosis. Clin Gastroenterol Hepatol 7: S48-S54, 2009.

41. Faulkner A, Rosen S and Norman C: The right information may matter more than frequency-place alignment: simulations of frequency-aligned and upward shifting cochlear implant processors for a shallow electrode array insertion. Ear Hear 27: 139-152, 2006. 